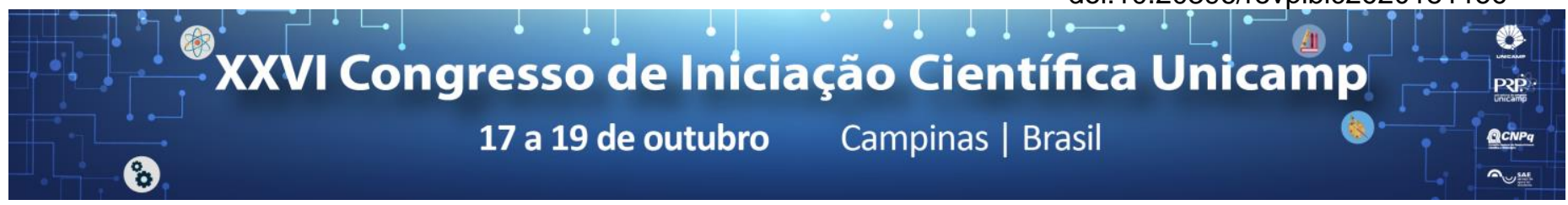

\title{
Glycerol electrooxidation in alkaline media on platinum surfaces modified by bismuth.
}

\author{
Rafael A. Vicente*, Matheus B. C. de Souza, Cléo T. G. V. M. T. Pires, Pablo S. Fernández
}

\begin{abstract}
We studied the glycerol electrooxidation reaction (GEOR) on Pt surfaces modified by $\mathrm{Bi}$ adatoms to understand the effect of catalyst strucutre on the activity and selectivity. This investigation was performed using a combination of electrochemical (cyclic voltammetry), chromatographic (HPLC) and spectroscopic (FTIR) techniques. Our results show that the presence of $\mathrm{Bi}$ blocks the reaction pathways that lead to $\mathrm{CO}$ formation, a poisoning intermediate, and increase the production rate of glyceric acid.
\end{abstract}

\section{Key words:}

Electrooxidation, Platinum, Bismuth.

\section{Introduction}

The growing of the biodiesel industry has led to a surplus in the glycerol $(\mathrm{GIOH})$ available on the market, since it is a co-product during biodiesel production. This caused a significant price drop, leading many research groups to investigate its chemical valorization ${ }^{1}$. In this context, the electrochemical oxidation is an option to this goal.

The electrooxidation offers the advantages of being performed at room temperature and ambient pressure, and the electrocatalysts can be easily modified ${ }^{2}$.

In this context, we modified $\mathrm{Pt}$, a common electrocatalyst, by depositing $\mathrm{Bi}$ adatoms on its surface, and investigated the effects of this modification on the GEOR in alkaline media.

\section{Results and Discussion}

The activity of Pt towards the GEOR was investigated using cyclic voltammetry (image 1). The Bi modification was performed by both partially covering the electrode surface, and directly adding $\mathrm{Bi}^{3+}$ ions to the electrolyte. Our results show that the highest activity (current) of the $\mathrm{Pt}-\mathrm{Bi}$ catalyst was after addition of $10^{-5} \mathrm{M} \mathrm{Bi}_{2} \mathrm{O}_{3}$ to the electrolyte containing $\mathrm{GIOH}$ in alkaline media.
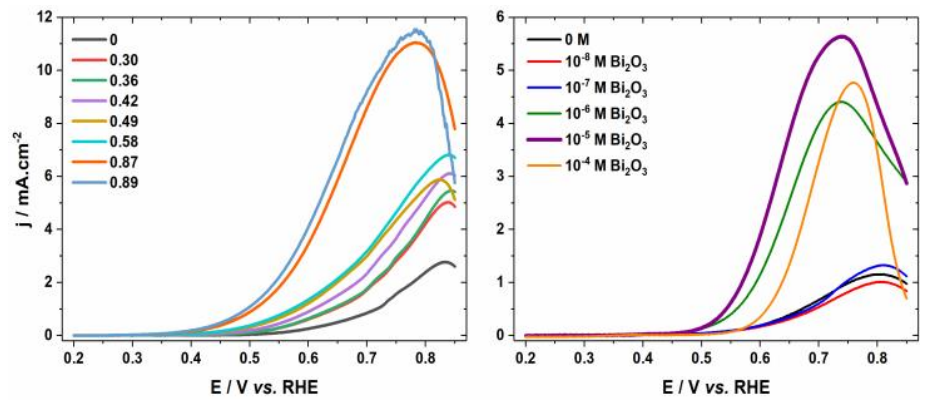

Image 1. (left) Positive scan of the $1^{\text {st }}$ cycle of the GEOR on $\mathrm{Pt}$ modified by partial $\mathrm{Bi}$ coverage, as indicated on the inset; (right) Positive scan of the $10^{\text {th }}$ cycle of the GEOR on $\mathrm{Pt}$, by adding varying amounts of $\mathrm{Bi}_{2} \mathrm{O}_{3}\left(0-10^{-4} \mathrm{M}\right)$ to the electrolyte. Base electrolyte is $0,1 \mathrm{M} \mathrm{NaOH}+0,1 \mathrm{M} \mathrm{GIOH}$, scan rate is $10 \mathrm{mV} . \mathrm{s}^{-1}$.

Product characterization was performed by in-situ FTIR on the $\mathrm{Pt}$ and $\mathrm{Pt}-\mathrm{Bi}$ catalysts (image 2). After Bi modification, no bands associated with $\mathrm{CO}$ adsorption on $\mathrm{Pt}$ were observed, and the band related to carbonate, corresponding to the $\mathrm{GlOH}$ total oxidation, was reduced.

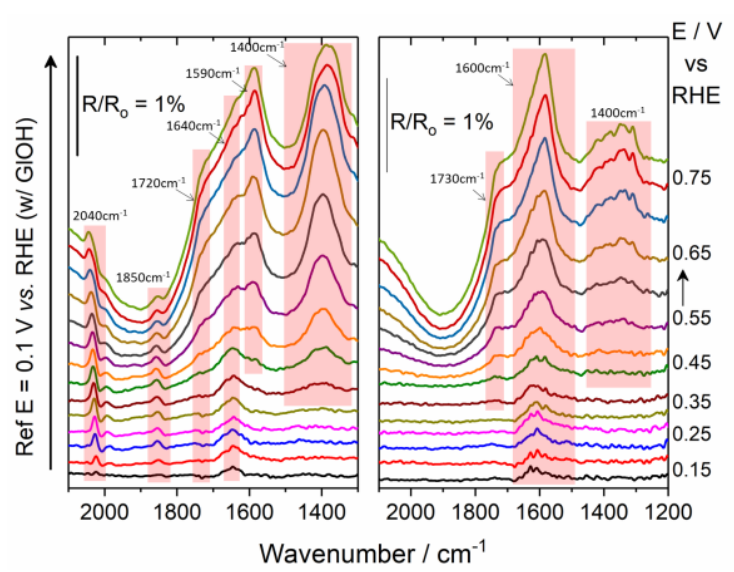

Image 2. Potential-dependent FTIR spectra for the clean (left) and Bi-modified (right) $\mathrm{Pt}$ electrodes. Electrolyte composition was $0,1 \mathrm{M} \mathrm{NaOH}+0,1 \mathrm{M} \mathrm{GlOH}$, with $10^{-5} \mathrm{M}$ $\mathrm{Bi}_{2} \mathrm{O}_{3}$ in the Pt-Bi catalyst, using a sweep rate of $2 \mathrm{mV} \cdot \mathrm{s}^{-1}$.

Further investigation with HPLC (image 3) revealed that the Bi-modification improved the production rate of glyceric acid by sevenfold.

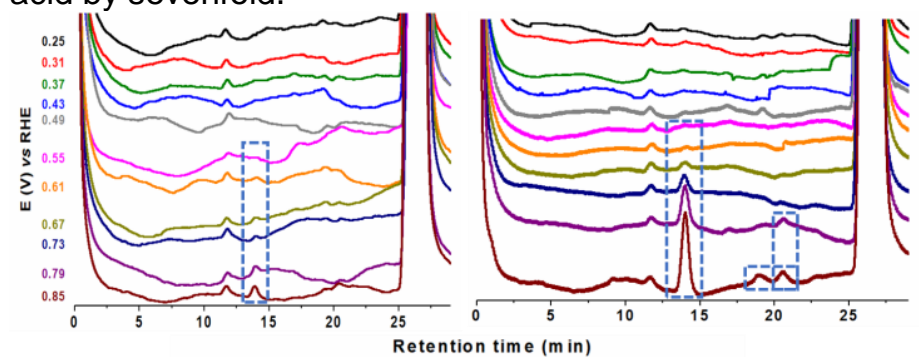

Image 3. Potential-dependent chromatograms for the clean (left) and Bi-modified (right) Pt electrode.

\section{Conclusions}

The addition of bismuth on the $\mathrm{Pt}$ causes a fivefold increase in the current density in the GEOR. The experiments using HPLC and in-situ FTIR demonstrated that the presence of bismuth inhibits the formation of $\mathrm{CO}$ (poisoning intermediate) and favors the formation of glyceric acid.

\section{Acknowledgements}

We thank FAPESP (Process number 2016/01365-0) and PRP-FAEPEX.

${ }^{1}$ Ciriminna, R. et. al. Eur. J. Lipid. Sci. Technol. 2014, 116(10), 1432.

${ }^{2}$ Kwon, Y. et. al. Top. Catal. 2014, 57, 1272. 